\title{
PERANCANGAN SISTEM PAKAR BERBASIS FMEA UNTUK MENGIDENTIFIKASI DAN MENDIAGNOSIS RISIKO KEGAGALAN PROSES PADA PROSES PRODUKSI REAR COMBINATION E83 TRUK HINO DUTRO
}

\author{
Winnie Septiani, Benza Hadi Perdana dan Johnson Saragih \\ Jurusan Teknik Industri, Universitas Trisakti \\ e-mail: winnie_septiani@yahoo.com ; johnson_saragih@yahoo.com
}

\begin{abstract}
ABSTRAK
Rear Combination E83 merupakan lampu belakang kombinasi untuk truk Hino yang diproduksi oleh PT. Ichokoh Indonesia. Saat ini perusahaan masih mengalami kesulitan dalam menemukan beberapa kegagalan proses yang berdampak pada kualitas produk yang dihasilkan. Penelitian ini bertujuan untuk merancang sistem pakar berbasis Failure Mode and Effect Analysis (FMEA) untuk mengidentifikasi dan mendiagnosis risiko kegagalan proses pada proses produksi Rear Combination E38 Truk Hino Dutro. Penelitian ini terbagi dalam tiga tahapan utama yaitu pertama mengidentifikasi kegagalan proses dengan menggunakan FMEA, kedua merancang model identifikasi dan diagnosis kegagalan proses produk Rear Combination E83 dan ketiga merancang sistem pakar untuk mengidentifikasi dan mendiagnosis kegagalan proses berbasis FMEA. Sistem pakar dirancang dengan menggunakan strategi penalaran exact reasoning dan strategi pelacakan forward chainning. Representasi pengetahuan dilakukan dengan menggunakan kaidah if then rule. Hasil identifikasi risiko kegagalan proses dengan menggunakan FMEA diperoleh hasil, terdapat 29 fungsi proses, dengan 51 jenis risiko kegagalan proses yang menimbulkan 29 efek yang disebabkan oleh 51 jenis penyebab dari kegagalan proses. Berdasarkan perhitungan nilai Risk Priority Number (RPN) disusun clustering pembagian nilai RPN menjadi 5 kelas yaitu $A, B, C, D$ dan E. Kelas A merupakan kelas yang memiliki risiko paling tinggi dan semakin menurun besaran risikonya pada kelas E. Representasi pengetahuan berdasarkan kaidah if then rule diperoleh 314 rule. Kombinasi dari masing-masing rule yang ada pada sistem ini diharapkan dapat membantu dalam mengidentifikasi dan mendiagnosis risiko kegagalan proses dan penyebabnya.
\end{abstract}

Kata Kunci: Kegagalan proses, FMEA, rule base, sistem pakar

\begin{abstract}
Rear Combination E83 is a combination rear light for Hino trucks manufactured by PT. Ichokoh Indonesia. Curently the company were still difficult to find some failure the process that impact on the quality of a product produced. This study aimed to design an expert system based on Failure Mode and Effect Analysis (FMEA) to identified and diagnosed the risk of process failure in the production process of Rear Combination E38 Hino Dutro Trucks. The study was divided into three main stages: first identifying the failure of the process by using FMEA, second designing the model identification and diagnosis of product failure Rear Combination E83 and third designing expert system to identify and diagnose failure of process based on FMEA. Expert system designed using exact reasoning and reasoning strategies strategy tracking forward chaining. Knowledge representation was done using the rule if then rule. The result of the risk identification process failure used FMEA, obtained results there were 29 function processes, with 51 types risk of failure processes that give rise to 29 the effect caused by the 51 types of causes the failure of the process. Based on the calculation of Risk Priority Number (RPN) value, the clustering of RPN was divided into 5 classes, namely $A, B, C, D$ and E. Class $A$ is the highest risk class and decreasing the risk level in class E. Representation of knowledge based on if then rule obtained 314 rules. The combination of each rule in the system is expected to assisted in identifying and diagnosing the risk process failure and its causes.
\end{abstract}

Keywords: Process failure, FMEA, rule base, expert system

\section{PENDAHULUAN}

\section{Latar Belakang}

PT. Ichikoh Indonesia merupakan salah satu perusahaan pembuat parts minor mobil seperti head lamp, rear combination lamp, door mirror dan small lamp. Dengan cakupan pasar yang cukup besar, tidak hanya pasar lokal tetapi juga ekspor khususnya ke Jepang dan Malaysia. Perusahaan berupaya agar dapat unggul dari pesaingnya baik dari segi harga maupun kualitas produknya. Oleh sebab itu pengendalian kualitas dan perbaikan proses 
produksi harus dilakukan untuk menghasilkan produk yang berkualitas.

Saat ini perusahaan masih mengalami kesulitan dalam menemukan beberapa kegagalan proses yang terjadi pada keseluruhan proses produksi. Kegagalan proses yang tidak teridentifikasi akan berdampak pada kualitas produk yang dihasilkan. Risiko tidak dapat dihilangkan seluruhnya, tetapi pengaruh dan dampaknya pada perusahaan dapat dikurangi dengan memilih penanganannya yang tepat [1] . Untuk mendapatkan kualitas yang baik, diperlukan suatu sistem yang dapat mempemudah proses identifikasi dan diagnosis kegagalan proses. Sehingga upaya penanggulannya dapat direncanakan sebelum risiko kegagalan itu terjadi.

Rear Combination E83 merupakan lampu belakang kombinasi untuk truk Hino yang diproduksi oleh PT. Ichokoh Indonesia. Rear Combination Lamps menjadi fokus dalam penelitian ini karena memiliki prosentase kecacatan produk yang paling tinggi dibandingkan produk lainnya. Mesin yang diamati dalam penelitian yaitu mesin Molding dengan proses pengeringan dan pemanasan bahan baku serta pencetakan, kemudian mesinmesin assembling.

Risiko kegagalan proses akan diidentifikasi dan dinilai dengan menggunakan Failure Mode and Effect Analysis (FMEA) yang didukung dengan menggunakan teknologi berbasis komputer yaitu Sistem Pakar.

FMEA merupakan tool analisis proaktif yang dapat mengidentifikasi dan mencegah satu kejadian dalam proses, produk atau sistem yang mengalami kegagalan. [2] menyebutkan dalam studinya, FMEA merupakan tool penilaian risiko dan perbaikan kualitas yang penggunaannya sangat luas dalam industri manufaktur. Tool ini merupakan kombinasi antara human knowledge dengan pengalaman (experience) untuk (1) mengindentifikasi kegagalan potensial dari suatu proses atau produk, (2) mengevaluasi kegagalan dari produk atau proses dan dampaknya, (3) membantu engineer untuk menentukan corrective action atau preventive measure dan (4) mengeliminasi atau mengurangi peluang terjadinya kegagalan. FMEA membantu dalam mengidentifikasi modus kegagalan yang diketahui dan dapat diduga sekarang kemudian merangking kegagalan tersebut berdasarkan dampak relatifnya terhadap produk. []ㅡ FMEA merupakan tool yang dapat digunakan untuk menentukan prioritas risiko dan memonitor efektivitas dari aktivitas kontrol risiko.

Informasi dan pengetahuan yang tersimpan dalam FMEA akan menjadi basis pengetahuan dalam perancangan sistem pakar. Tahap pembentukan sistem pakar menurut [4] meliputi akuisisi pengetahuan, representasi pengetahuan, pengembangan mesin inferensi.

\section{Tujuan Penelitian}

Penelitian ini bertujuan untuk merancang sistem pakar berbasis Failure Mode and Effect Analysis (FMEA) untuk mengidentifikasi dan mendiagnosis risiko kegagalan proses pada proses produksi Rear Combination E38 Truk Hino Dutro.

\section{METODOLOGI PENELITIAN Pengumpulan Data}

Metode pengumpulan data yang digunakan adalah sebagai berikut:

1) Observasi langsung, untuk mengamati proses produksi Rear Combination dan juga mengamati permasalahan kegagalan proses yang terjadi pada keseluruhan proses.

2) Wawancara, dengan pihak perusahaan khusus di Departemen Produksi.

3) Mempelajari data historis perusahaan seperti data kecacatan produk dan data control plan produk.

\section{Tahapan Penelitian}

Penelitian ini terbagi dalam tiga tahapan utama yaitu:

1. Mengidentifikasi risiko kegagalan proses dengan menggunakan Failure Mode and Effect Analysis (FMEA)

a. Melengkapi tabel FMEA (penyebab dan dampak pontensial);

b. Menentukan penilaian kuantitatif dari Severity (S), Occurrence (O) dan Detectability (D);

$\mathrm{S}=$ Tingkat keparahan yang ditimbulkan dari kegagalan yang berakibat kepada produk 


$$
\begin{aligned}
\mathrm{O}= & \text { Peluang terjadinya kegagalan. } \\
\mathrm{D}= & \text { Kemampuan kegagalan dapat } \\
& \text { dideteksi. }
\end{aligned}
$$

c. Menghitung Risk Priority Number (RPNs), diurut menurun (descending). Kemudian tentukan RPN tertinggi dan terrendah;

$$
R P N=S \times O \times D
$$

d. Melakukan perbaikan dan hitung kembali RPNs terbaru hasil perbaikan.

\section{Merancang model identifikasi dan diagnosis risiko kegagalan proses}

Perancangan model identifikasi dan diagnosis kegagalan proses Rear Combination E83, meliputi: penyusuanan katalog risiko, pengelompokan (Clustering) nilai Risk Priority Number (RPN) dan Tree Diagram.

3. Merancang sistem pakar untuk mengidentifikasi dan mengdiagnosis kegagalan proses berbasis FMEA

Strategi penalaran yang digunakan adalah Forward Chaining, penalaran dimulai dari fakta terlebih dahulu untuk menguji kebenaran hipotesis [5]. Metoda pencarian dan pelacakan yang digunakan adalah Metoda Best First Search (Pencarian terbaik pertama), metode ini merupakan kombinasi dari metode Depth First Search dan Metode Breadth First Search [6]. Kombinasi kedua metode ini sangat dimungkinkan karena pencarian solusi tidak hanya melihat satu lintasan akan tetapi masih memungkinkan untuk berpindah ke lintasan lain apabila lintasan lain tersebut lebih menjanjikan untuk mendapatkan solusi [7].

Rule diformulasikan dalam bentuk linguistik dan diekspresikan dalam bentuk IFTHEN. Proposisi yang mengikuti IF disebut sebagai anteseden, sedangkan proposisi yang mengikuti THEN disebut sebagai konsekuen.

$$
\text { R1 : IF x adalah Mi THEN y adalah Ni }
$$

\section{Verifikasi dan Validasi}

Validasi model konseptual dilakukan dengan menggunakan metode face validity yaitu dengan cara menanyakan secara langsung kepada pakar yang memiliki pengetahuan dan pengalaman dalam rantai pasok agroindustri susu [8]. Verifikasi model dilakukan dengan menggunakan metode blackbox testing [9]. Validasi operasional dilakukan dengan menjalankan model dan hasilnya dibandingkan dengan data riil.

\section{HASIL DAN PEMBAHASAN}

\section{Identifikasi Risiko Kegagalan Proses dengan} FMEA

Berdasarkan hasil identifikasi diperoleh 51 kegagalan proses pada proses produksi Rear Combination, diantaranya (1) Masih terdapat biji plastik yang mengakibatkan keretakan, sempal dan gores, (2) Kesalahan bentuk produk, (3) Housing NG pada saat perakitan, (4) Warna produk yang dihasilkan buram atau kusam, (5) Hasil peleburan melengkung, tidak sempurna, (6) NG fungsi bulp, (7) Hasil pengepresan tidak sempurna, (8) Kesulitan dalam setting ke body mobil, (9) Gasket miring, (10) Bulp putus dan tidak berfungsi dengan baik, (11) Skrup miring, (12) Barang NG saat diterima konsumen. Identifikasi penyebab pada kegagalan proses tersebut dilakukan dengan menggunakan Diagram Isikawa (Gambar 1).

Risiko kegagalan proses, penyebab, dampak dan upaya penanggulangannya dipetakan dengan menggunakan Failure Mode and Effect Analysis (FMEA). Contoh pemetaannya dengan FMEA dapat dilihat pada Tabel 1. Risiko kegagalan proses diukur dengan tiga dimensi risiko yaitu Severity (Tingkat keparahan), Occurence (Peluang kejadiannya) dan Detectability (Kemampuan untuk dideteksi). Kemudian dihitung nilai RPN nya, sebagai perkalian dari Severity (S), Occurence (C) dan Detectability (D). 


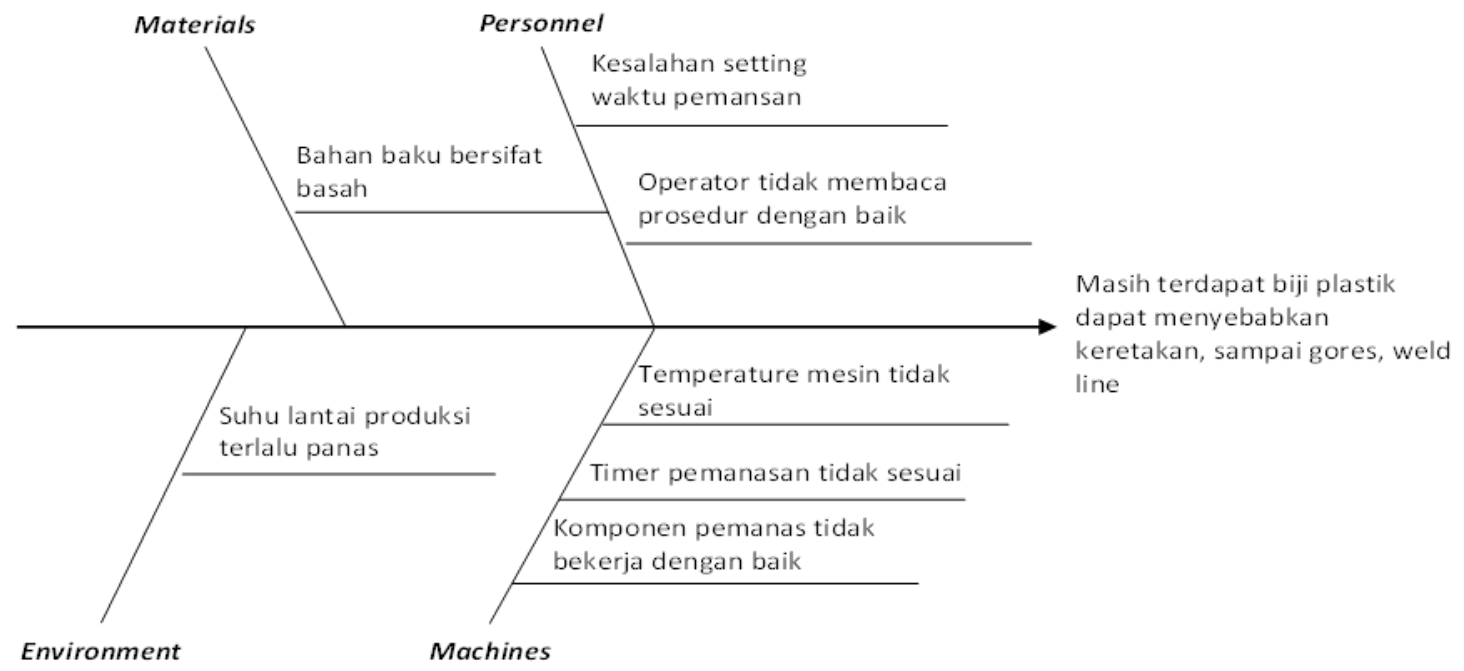

Gambar 1. Identifikasi Penyebab Kegagalan Proses dengan Diagram Ishikawa

Tabel 1. Pemetaan Risiko Kegagalan Proses Pembuatan Rear Combination E83 dengan Menggunakan FMEA

\begin{tabular}{|c|c|c|c|c|c|}
\hline Proses & Kegagalan Proses & Dampak & Penyebab & $\begin{array}{c}\text { Kontrol } \\
\text { yang } \\
\text { dilakukan }\end{array}$ & $\begin{array}{c}\text { Upaya } \\
\text { Penanggulangan }\end{array}$ \\
\hline G1 & $\begin{array}{l}\text { Waktu pemanasan } \\
\text { BB tidak sesuai } \\
\text { dengan Standar } \\
\text { (G1.1) } \\
\text { Temperatur } \\
\text { pemanasan yang } \\
\text { tidak sesuai dgn } \\
\text { standar (G1.2) }\end{array}$ & $\begin{array}{l}\text { Masih terdapat } \\
\text { biji plastik dalam } \\
\text { bahan baku, } \\
\text { produk retak, } \\
\text { permukaan kasar, } \\
\text { sempal, terdapat } \\
\text { gorean, weld line }\end{array}$ & $\begin{array}{l}\text { Komponen } \\
\text { pemanas pada } \\
\text { mesin molding } \\
\text { tidak bekerja } \\
\text { dengan baik }\end{array}$ & $\begin{array}{l}\text { Leader } \\
\text { mengawasi } \\
\text { cara kerja } \\
\text { operator } \\
\text { Melakukan } \\
\text { pengecekan } \\
\text { komponen- } \\
\text { komponen } \\
\text { mesin }\end{array}$ & $\begin{array}{l}\text { Setting waktu } \\
\text { pemanasan pada mesin } \\
\text { Molding harus sesuai } \\
\text { prosedur kerja } \\
\text { Melakukan kalibrasi } \\
\text { mesin sebelum } \\
\text { beroperasi }\end{array}$ \\
\hline G3 & $\begin{array}{l}\text { Pemotongan gate } \\
\text { overcut (G3.1) }\end{array}$ & $\begin{array}{l}\text { Housing NG pada } \\
\text { saat perakitan }\end{array}$ & $\begin{array}{l}\text { Kurangnya } \\
\text { penerangan }\end{array}$ & Tidak ada & $\begin{array}{l}\text { Menambah penerangan } \\
\text { di lini produksi yang } \\
\text { bersangkutan }\end{array}$ \\
\hline \multirow[t]{2}{*}{ G4 } & $\begin{array}{l}\text { Proses embarian } \\
\text { overcut (G4.1) }\end{array}$ & $\begin{array}{l}\text { Housing NG pada } \\
\text { saat perakitan }\end{array}$ & $\begin{array}{l}\text { Operator tergesa- } \\
\text { gesa dalam } \\
\text { bekerja }\end{array}$ & Tidak ada & $\begin{array}{l}\text { Menambah penerangan } \\
\text { di lini produksi yang } \\
\text { bersangkutan }\end{array}$ \\
\hline & $\begin{array}{l}\text { Proses pembarian } \\
\text { tidak terpotong } \\
\text { sempurna (G4.2) }\end{array}$ & & $\begin{array}{l}\text { Pisau cutter } \\
\text { tumpul }\end{array}$ & $\begin{array}{l}\text { Pengecekan } \\
\text { alat bantu } \\
\text { produksi }\end{array}$ & $\begin{array}{l}\text { Tool alat bantu selalu } \\
\text { diganti dan dicek secara } \\
\text { berkala }\end{array}$ \\
\hline \multirow[t]{2}{*}{ G7 } & $\begin{array}{l}\text { Panas pada saat } \\
\text { memasang cetakan } \\
\text { tail stop lens pada } \\
\text { ruang cetak (G7.1) }\end{array}$ & $\begin{array}{l}\text { Kesalahan bentuk } \\
\text { produk, serta hasil } \\
\text { cetakan yang } \\
\text { tidak rapih atau }\end{array}$ & $\begin{array}{l}\text { Suhu ruang cetak } \\
\text { yang tinggi }\end{array}$ & $\begin{array}{l}\text { Cek suhu } \\
\text { ruang cetak }\end{array}$ & $\begin{array}{l}\text { Operator harus } \\
\text { menggunakan peralatan } \\
\text { K3 }\end{array}$ \\
\hline & $\begin{array}{l}\text { Bahan baku SHM } \\
\text { VH } 112 \text { yang } \\
\text { masuk ke dalam } \\
\text { cetakan tidak } \\
\text { merata (G7.2) }\end{array}$ & $\begin{array}{l}\text { tidak presisi tidak } \\
\text { sesuai spesifikasi } \\
\text { yang diinginkan }\end{array}$ & $\begin{array}{l}\text { Dimensi cetakan } \\
\text { tail stop lens } \\
\text { kurang sesuai } \\
\text { spesifikasi, } \\
\text { terdapat kotoran } \\
\text { pada cetakan }\end{array}$ & $\begin{array}{l}\text { Pemeriksaan } \\
\text { kondisi } \\
\text { cetakan tail } \\
\text { stop lens }\end{array}$ & $\begin{array}{l}\text { Melakukan pengecekan } \\
\text { ulang spesifikasi } \\
\text { cetakan tail stop lens } \\
\text { dan pemeriksaan } \\
\text { kondisi fisiknya }\end{array}$ \\
\hline
\end{tabular}

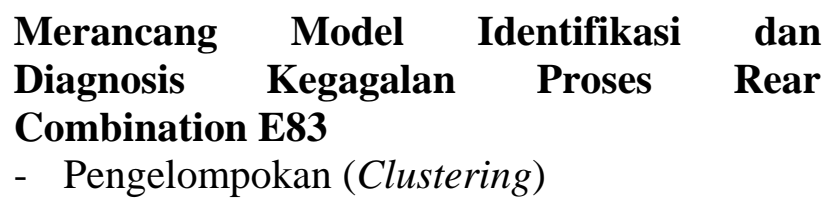

Merancang Model Identifikasi dan Combination E83

- Pengelompokan (Clustering)

\section{.}

mengelompokkan masalah berdasarkan nilai Risk Priority Number (RPN), yang terbagi menjadi 5 kelas yaitu A, B,C, D dan E. 
Tujuannya adalah untuk memfokuskan penyelesaian permasalahan. Hasil clustering dapat dilihat pada Tabel 2. Kelas A merupakan kelas yang memiliki tingkat keparahan tertinggi, sedangan kelas E merupakan kelas yang memiliki tingkat keparahan terendah.

Formula:

Clustering $=\frac{\mathrm{RPN} \max -\mathrm{RPN} \min }{\text { Jumlah Kelas }}$

Tabel 2. Clustering Nilai RPN

\begin{tabular}{cc}
\hline Kelas & Rentang \\
\hline A & $280-224,4$ \\
B & $224,4-168,8$ \\
C & $168,8-113,2$ \\
D & $113,2-57,6$ \\
E & $57,6-2$ \\
\hline
\end{tabular}

- Tree diagram untuk fungsi proses memanaskan PP SHM 3769.

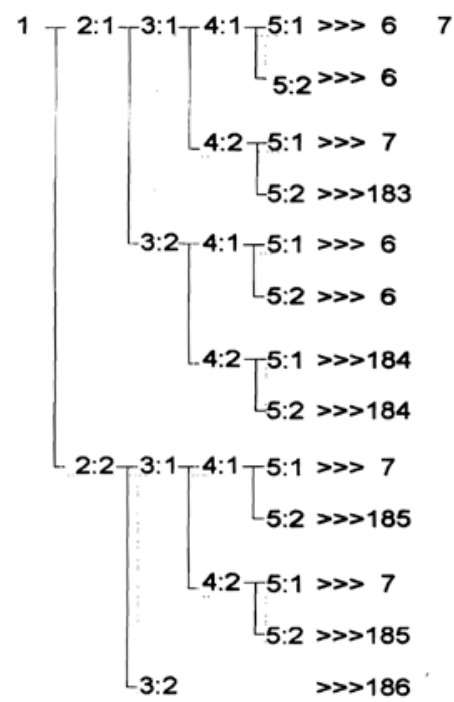

Gambar 2. Tree diagram untuk fungsi proses PP SHM 3769
Model hubungan integrasi FMEA dan Sistem Pakar untuk mengidentifikasi dan mendiagnosis risiko dapat dilihat pada Gambar 3.

\section{Merancang Sistem pakar untuk Mengidentifikasi dan Mendiagnosis Risiko Kegagalan Proses Berbasis FMEA \\ Penyusunan rule base dengan} menggunakan IF THEN rule (Tabel 3), menghasilkan 314 rule. Dengan menggunakan production rule yang merupakan konsisi aksi (jika-maka) [10], suatu konsekuensi atau konklusi dinyatakan dalam bagian THEN itu benar, jika bagian IF kaidah tersebut juga benar atau sesuai dengan kondisi tertentu. If then rule ini diolah dalam software winexys untuk membentuk suatu kondisi berdasarkan aturan pengkodingan pada Tabel 3.

Penalaran bersifat pasti berarti penalaran dengan kebenaran 100 persen sedangkan masalah ketidakpastian ditangani dengan menggunakan metode Certainty Factor (CF). CF merupakan nilai numerik yang menunjukan nilai kepercayaan suatu parameter pada saat pelacakan. Nilai CF ditentukan saat membentuk basis pengetahuan dan ditentukan saat konsultasi dengan pakar. Interpretasi nilai Certainty Factor dapat dilihat pada Tabel 4 dan range untuk nilai Certainty Factor (Gambar 4).

Sistem pakar dirancangan dengan menggunakan software Winxys (Gambar 3). Minimum spesifikasi komputer yang diperlukan adalah Processor $1 \mathrm{GHz}$, Memory (RAM) 256 MB, Harddisk dengan kapasitas 5 GB,VGA card 16 MB dan Monitor VGA (512 color).

Tabel 3. Penyusunan Rule Base

\begin{tabular}{cccccccccccc}
\hline \multirow{2}{*}{ Rule } & \multicolumn{4}{c}{ IF } & \multicolumn{4}{c}{ AND } & \multicolumn{2}{c}{ AND } & \multicolumn{2}{c}{ AND } & \multirow{2}{*}{ THAN } \\
\cline { 2 - 9 } & $\mathrm{X}_{1}$ & $\mathrm{X}_{2}$ & & $\mathrm{X}_{3}$ & & $\mathrm{X}_{4}$ & & $\mathrm{X}_{4}$ & & \\
\hline 1 & 1 & 2 & yes & 3 & Yes & 4 & yes & 5 & yes & 6.7 \\
2 & 1 & 2 & Yes & 3 & Yes & 4 & Yes & 5 & Yes & 6 \\
$\ddot{14}$ &.. &.. &.. &.. &.. &. &.. &.. &.. &.. \\
15 & 8 & 9 & Yes & 10 & Yes & 11 & Yes & 12 & Yes & 13,14 \\
.. &.. & &.. &.. &.. &.. &.. &.. &.. &.. &.. \\
298 & 164 & 165 & No & 16 & Yes & 167 & Yes & 168 & Yes & 170 \\
.. &.. &.. &.. & & & & & & & \\
314 & 179 & & & & & & & & & \\
\hline
\end{tabular}




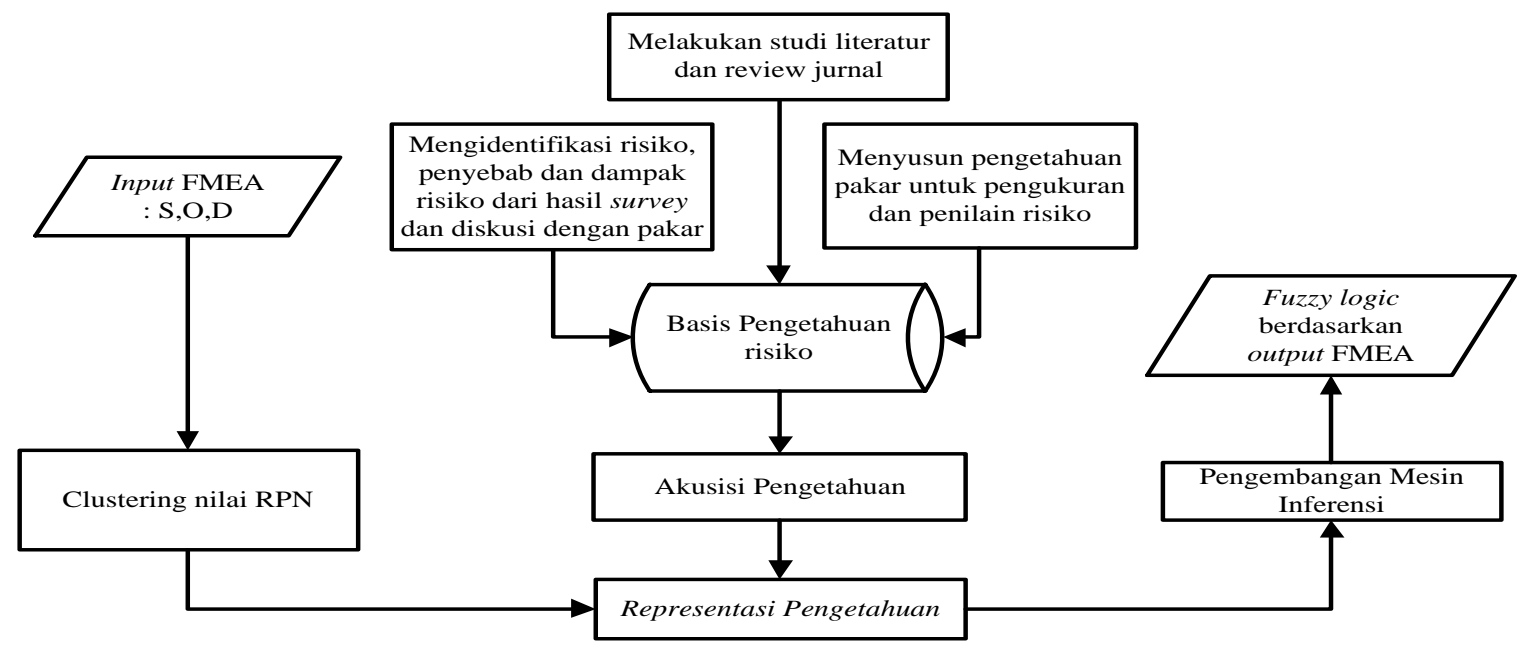

Gambar 3. Model Hubungan FMEA dengan Penyusunan Basis Pengetahuan untuk Sistem Pakar

\begin{tabular}{lcccc} 
False & Possibly-False & UNKNOWN & Possibly-True & True \\
\hline-1 & 0 & 1 \\
& & & \\
& & Range of Disbelief & C & Range of Belief
\end{tabular}

Gambar 4. Range untuk Nilai Certainty Factor (CF) [11]

Tabel 4. Interpretasi Nilai Certainty Factor (CF) [11]

\begin{tabular}{lc}
\hline \multicolumn{1}{c}{ Uncertain Term } & CF \\
\hline Definitely not & $-1,0$ \\
Almost certainly not & $-0,8$ \\
Probably not & $-0,6$ \\
Maybe not & $-0,4$ \\
Unknown & $-0,2$ to 0,2 \\
Maybe & 0,4 \\
Probably & 0,6 \\
Almost Certainly & 0,8 \\
definitely & 1,0 \\
\hline
\end{tabular}

\section{Pengujian Sistem}

Pengujian model dan sistem dilakukan dalam beberapa tahap:

\section{Validasi model konseptual}

Validasi model dilakukan dengan menggunakan metode face validity. Validasi model ini dilakukan dengan cara diskusi secara langsung dengan pakar yang memiliki pengetahuan dan pengalaman terkait dengan kegagalan proses produk Rear Combination E83.

\section{Verifikasi model}

Verifikasi model dilakukan dengan menggunakan metode blacktesting. Pengujian dilakukan dengan memeriksa kesesuaian antara model yang tersusun dengan sistem yang dirancang.

\section{Validasi operasional}

Pengujian dilakukan dengan cara menjalankan sistem dan hasilnya dibandingkan dengan hasil penilaian dari pakar.

\section{KESIMPULAN}

Hasil dari identifikasi dan diagnosis kegagalan proses dengan menggunakan FMEA pada proses produksi Rear Combination E83 diperoleh 29 fungsi proses, 51 jenis kegagalan, 29 dampak dan 51 penyebab kegagalan proses. Untuk setiap kegagalan proses ditentukan upaya penanggulangannya berdasarkan pendapat pakar.

RPN tertinggi ada pada kegagalan proses bahan baku SHM 3756, SHM VH 112, PMMA 001 dan PMMA tidak merata dan setting temperatur pengeringan di mesin hopper dryer 


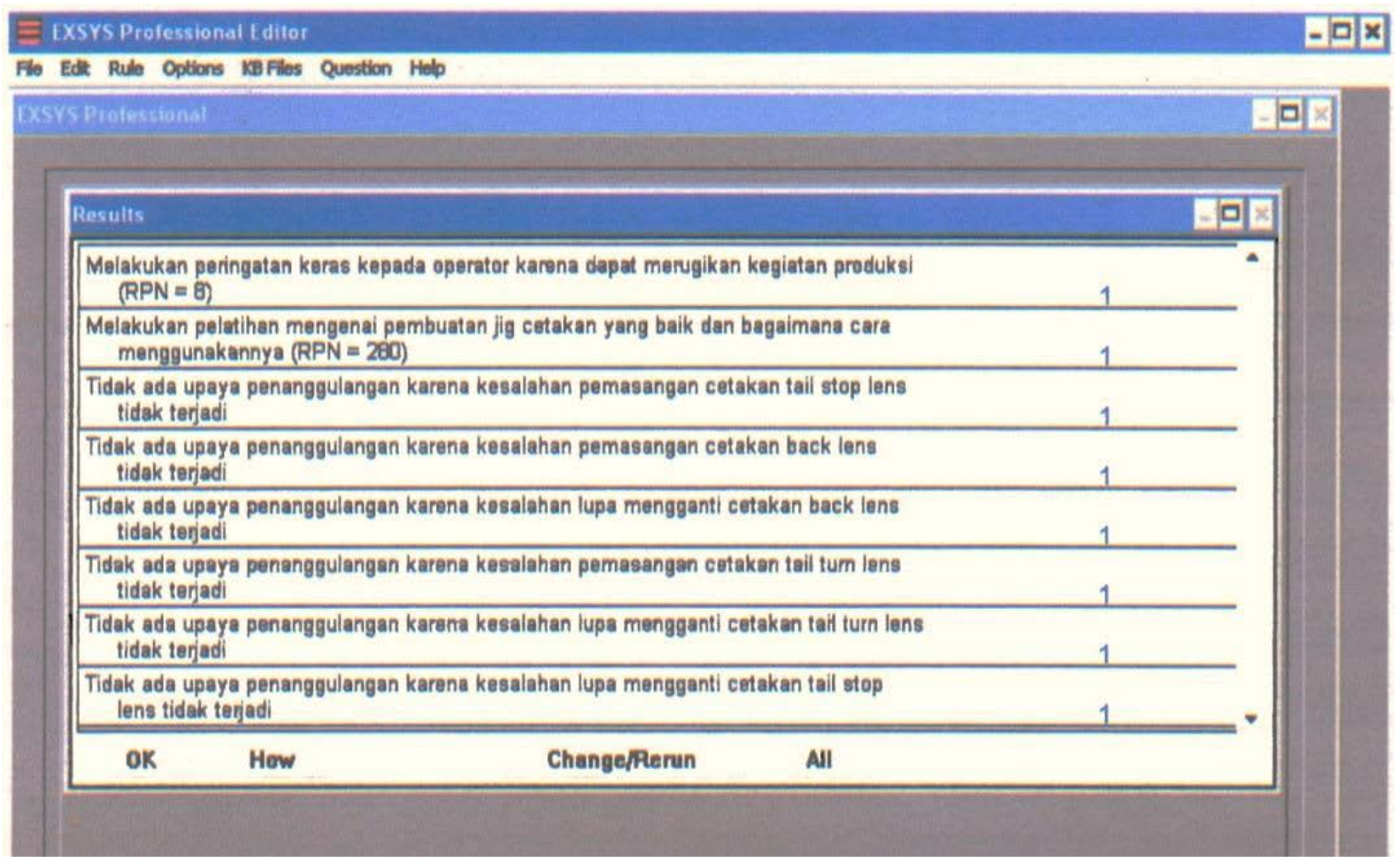

Gambar 5 Sistem Pakar untuk Mengidentifikasi dan Mendiagnosis Risiko Kegagalan Proses

yang tidak sesuai dengan kapasitas bahan baku tails stop lens.

Jalannya program dimulai dari pemilihan efek yang terjadi, kemudian menuju ke pertanyaan iya/tidak untuk kegagalan proses, identifikasi penyebab kegagalan. Setelah semua pertanyaan dijawab oleh user maka akan keluar upaya penanggulangan dan nilai RPN nya. Sistem pakar ini diharapkan mampu mendiagnosis dan mengidentifikasi kegagalan proses produksi Rear Combination E83.

\section{DAFTAR PUSTAKA}

[1] Manuj, I. and Mentzer, J. T., (2008) Global supply chain risk management strategies, International Journal of Physical Distribution \& Logistics Management, No. 38, PP. 192-223.

[2] Yeh, R. H. and Hsieh, M., (2007) Fuzzy assessment of FMEA for a sewage plant, Journal of the Chinese Institute of Industrial Engineers, No. 24, PP. 505-512.

[3] Perez, J. R. and Rodriguez, M. E. P., (2012) Fail-Safe FMEA Combination of quality tols keeps risk in check, Quality Progress, No. 45, PP. 30-36.
[4] Marimin, (2005). Teori dan Aplikasi Sistem Pakar dalam Teknologi Manajerial. Bogor: IPB Press.

[5] Turban, E., (1992). Experts System and applied artificial Intelligence. New York: Macmillan Publishing Company.

[6] Jakson, P., (1998). Introduction to Experts System. Edinburgh Gate: Addison Wesley Longmann Limited.

[7] Mesker, L. and Liebowitz, J., (1994). Design and Development of Expert System and Neuron Networks. New York: Macmillan Publishing Company.

[8] Sargent, R. G., (2007) Verification and validation of simulation models, Proceedings of the 2007 Winter SImulatio Conference, PP. 124-137.

[9] Sommerville, I., (2011). Software Engineering vol. 9. California (US): Addison-Wesley.

[10]Giarratano, Joseph, C., and Riley, G. D., (2005). Expert System Principles and Programming. Massachusetts: Thompson Learning Inc.

[11]Durkin, J., (1994). Expert Systems Design and Development. New Jersey: Prentice Hall International,Inc. 